\title{
Distributional Considerations for Transboundary Risk Governance of Environmental Threats
}

\author{
Adam Rose ${ }^{1}$
}

Published online: 17 December 2018

(C) The Author(s) 2018

\begin{abstract}
Most policy analyses of both short-term and long-term disasters focus on aggregate impacts of their costs and the benefits of policy remedies. Distributional considerations relating to the costs of these disasters and the benefits of their risk management, however, are very important in many cases. This article examines two broad categories of cases in terms of distributional considerations. The first category is where transboundary considerations strongly affect risk governance, as in the case of climate change. The second relates to ordinary, short-term disasters, which include fewer, but still important, transboundary issues. Climate change policy requires information regarding the distribution of impacts and policy responses across countries because it is a global problem. Conventional disasters involve transboundary considerations much less frequently, so the attention typically shifts to the distribution of benefits and costs within a jurisdiction. In both cases distributional information is needed to evaluate the equity of policies and to provide information for public participation in the policy process. This article offers modeling and policy approaches to address these issues.
\end{abstract}

Keywords Climate change $\cdot$ Disasters $\cdot$ Distributional effects · Policy analysis - Risk governance $\cdot$ Transboundary impacts

Adam Rose

adamzros@price.usc.edu

1 Price School of Public Policy, University of Southern California, Los Angeles, CA 90089, USA

\section{Introduction}

Environmental threats range from localized ones like landslides through regional ones like major earthquakes and tsunamis to truly global ones like climate change. Most of these threats typically transcend political boundaries, which complicates decision making to address them. Solutions must be made in the context of a multiplicity of jurisdictions, not only horizontally, but vertically with respect to ascending layers of the government hierarchy from local to national and sometimes to international.

This article presents issues and recommendations that help resolve transboundary risk governance issues in relation to short-term (natural hazard) and long-term (climate change) threats. The value of considering distributional aspects of these issues on several fronts merits emphasis, due to the transboundary nature of the threats, the divergence of benefits and costs among parties at interest, the differing abilities of the parties to share the cost burden, and the institutional mechanisms to address the issues. In addition, a summary of some methods that can be used to estimate and frame the distributional information is provided.

Foremost of the distributional issues are those relating to equitable, or fair, burden-sharing. In many cases there is no supraauthority to mandate a solution, and hence it must be made on the basis of voluntary cooperation. Entities are unlikely to enter an agreement unless they believe they are being treated fairly, and some are concerned that others are treated fairly as well. Moreover, there is no universal consensus on the best concept of equity, so this often becomes the thorny first hurdle to cross in attaining successful agreements.

Information on the distribution of gains and losses from a threat and on the impacts of the policies to address it are 
needed in most cases. The matter extends to considerations within countries at the local, state/provincial, and sometimes larger regional level, and to multicountry and global levels where transboundary considerations are extensive. Here there is also a need to focus the analysis on how individuals, as opposed to aggregates, are affected in order to facilitate the public participation process.

Conventional benefit-cost analysis (BCA) typically only provides aggregate information, which is only of limited help in this regard. The aforementioned considerations relate to the normative economic realm of public policy. Distributional information also has positive economic implications, however, because it can be used as a predictive tool of the outcome of many decision processes. For example, in a democratic/majority-rule context, information on how many people stand to gain or lose is as important as how much each one gains/loses.

This article is written with an eye to addressing the Renn and Schweizer (2009) concepts for inclusive risk governance of the environment. These are: (1) inclusion; (2) diverse actors; (3) integrated knowledge; (4) decision processes; (5) values; (6) risks; and (7) criteria.

The article is organized into four sections. Next we discuss distributional issues relating to climate change policy, mainly with respect to their burden-sharing among countries. Then we discuss the important role of distributional information for public participation in environmental and natural resource decision making from both a normative and positive economic perspective. Similarities and differences between these two contexts are discussed throughout, including how lessons learned from one domain can be applied to the other. We conclude with an agenda for future research.

\section{Distributional Aspects of Climate Change Policy}

In this section, we explain how distributional concerns among countries are crucial to global climate agreements, tracing the evolution of various approaches to overcoming the burden-sharing issue. We also indicate how a cap and trade system can accommodate various equity principles.

\subsection{Background}

The major driver of climate change is a set of greenhouse gases (GHGs) emitted by human actions, such as the extraction and combustion of fossil fuels, the making of cement, burning of forests, and tilling of agricultural land. These gases build up in the atmosphere and exacerbate the "greenhouse effect," whereby ultraviolet light is able to penetrate the gases, but, once transformed into infrared radiation upon hitting the Earth's surface, the heat associated with the light is then trapped between the surface and the upper atmosphere by these gases. The result is not only a warming of temperatures but a general scrambling of weather patterns that can result in increased rainfall. More recently, scientists are concluding that the increase in ocean temperature is giving rise to more severe hurricanes as well (IPCC 2014).

Economists label GHGs as stock pollutants, because they build up in the atmosphere, in contrast to more ordinary flow pollutants that simply dissipate rapidly to the Earth's surface. Atmospheric mixing spreads these pollutants past even the broadest political boundaries. The fact that GHGs are a "globally-mixed pollutant" means that the same damages wrought from their emission and the same benefits from curbing them takes place no matter where in the world these pollutants are generated or mitigated. All countries contribute to the GHG emission problem, both rich and poor. For example, it is estimated that by the year 2020, China will be responsible for $24 \%$ of global emissions, the United States 13\%, Europe 8\%, and India 7\%.

A global problem like this requires a global solution, meaning that all countries must be involved. Climate agreements are made difficult in the first place by the uncertainties regarding the future course of climate change and the damages it will cause. It is also complicated by the costs of GHG mitigation and sequestration, though there is increasing evidence of low-costs and cost-saving options such as energy efficiency improvements and land-use planning (IPCC 2014). Complicating the situation, however, is an inherent feature of common property resources like the atmosphere-the "free-rider" problem. Essentially, those countries that do not take steps to reduce their own GHG emissions can benefit from the actions of others who do.

Unfortunately, there is no supranational authority to dictate a solution to the problem. It requires voluntary action on the part of countries. Rose (1990) and many others since have emphasized that the fair sharing of the cost burden of climate change is necessary to attain agreement, and that equity could be a rallying point for such an agreement. The prevalent approach during the first 20 years of climate negotiations was a top-down one, whereby countries tried to agree on an equity principle or combination of principles for all to use as a basis for distributing the burden. This process got bogged down because of the failure of countries to agree on these principles, and, in fact, by nations pointing to various principles as an excuse to avoid signing the major successful accord during this negotiating period, including the Kyoto Protocol (Andresen 2015). China, for example, claimed that it was unfair to ask developing countries to share the cost burden given their relative lack of resources and the fact that currently industrialized countries had not had to 
make similar sacrifices at their "takeoff" stages of economic development. The United States, on the other hand, used the fact that major developing countries were not taking part in the protocol as an excuse for not joining as well. In general, developing countries preferred equity principles that favored their status, such as egalitarian, ability to pay, vertical, and Rawlsian equity, whereas industrialized countries preferred equity principles that shared the burden more evenly [see the definitions of various equity principles in the first column of Table 1 , adapted from Rose et al. (1998)].

The logjam was recently broken at the 21 st Conference of the Parties (COP) to the United Nations Framework Convention on Climate Change (UNFCCC) held in Paris in late 2015, where 195 countries offered pledges intended to reduce GHG emissions so as to avoid global mean temperatures more than $2^{\circ} \mathrm{C}$ beyond preindustrial levels. These Intended Nationally Determined Contributions (INDCs) represented a bottom-up approach to the negotiations (Rayner 2010) in that each country dictated its own level of GHG mitigation (UNFCCC 2016). Ironically, many developing countries (for example, Brazil with a $41 \%$ reduction and Mexico with a $25 \%$ reduction) departed from their earlier positions by offering pledges at the level of many industrialized countries. Rose et al. (2017, 2018) make the point that developing countries may have "pledger's remorse" once they begin comparing their own promised contribution with those of other countries. Moreover, scientists suggest that the $2^{\circ} \mathrm{C}$ target (ceiling) is inadequate to avoid major damages from climate change, and recommend a $1.5^{\circ} \mathrm{C}$ target. Bretschger (2016) and others see equity principles returning as a major consideration in negotiations to strengthen the target.

\subsection{The Cap \& Trade Policy Instrument}

Once a policy goal is established, the next issue is how to implement it. Economists generally consider three categories of such instruments in the environmental realm (Rose and Stevens 2017). The first is the traditional regulation (command and control) approach, where strict limits on emissions are imposed. The inflexibility of this approach is a liability in several ways, the major one being the likelihood that it will not achieve the desired goal at the least cost, with a secondary concern that equity issues cannot be addressed head on. The other two approaches are preferred, as they are incentive-based, with both desirable efficiency and equity properties. A carbon tax would elicit GHG mitigation by emitters, according to their own choice, in an effort to avoid the tax. The result would yield an overall cost-minimizing outcome, with equity being achieved by the redistribution of tax revenues according to various equity principles. The third approach is based on the principle of giving polluters a stake in the environment and thereby making them "internalize" the ramifications of their actions by taking into consideration their opportunity costs. The major example of this is GHG emissions trading, or cap \& trade, whereby each emitter is freely granted emission allowances, which together represent the overall "cap," and then are allowed to "trade" the allowances so as to achieve the overall least-cost of compliance. Equity is embodied into the instrument in terms of the initial allocation of allowances. Table 1 presents the manner in which various equity principles can be achieved through this initial allocation. ${ }^{1}$

Cap \& trade has been the preferred policy instrument for many years, though there is some recent momentum for a carbon tax approach. Successful examples of emissions trading are the US Clean Air Act amendments of 1990, which implemented this policy to reduce sulfur dioxide omissions that contribute heavily to acid rain, the European (GHG) Emissions Trading System (ETS), the (Northeastern/Mid-Atlantic US States) Regional Greenhouse Gas Initiative (RGGI), and more recent emissions trading systems in California and some Chinese provinces. While these systems have incurred some problems, overall the assessment is that they have been successful (Ellerman and Buchner 2007). Another attractive feature of cap \& trade is that equity issues can be addressed head-on by the allocation of allowances among countries without undercutting economic efficiency (thereby overcoming the standard equity-efficiency trade-off that plagues so many policies, such as unemployment insurance) (Rose et al. 1998). Moreover, this policy instrument is compatible with the bottom-up approach, whereby each country decides on its own initial allocation of allowances (projected baseline emissions minus their pledge) (Rose et al. 2017).

The setting of the $2^{\circ} \mathrm{C}$ target and the individual country pledges at the Paris COP then represent just the first step in the process of achieving this goal. Countries must still agree on a policy instrument to implement pledges. They could decide to have every country do so in isolation, but most realize that this would be a relatively costly alternative (equivalent to a set of fixed quotas of emission reductions akin to the strict regulatory approach). Momentum is building to establish emissions trading systems, though acknowledging that not all emitting activities

\footnotetext{
1 The carbon tax and cap \& trade approach are often compared. The equivalence is best examined when allowances are auctioned to the highest bidder, rather than freely granted. Initially, from an equity standpoint this represents a type of "market justice." However, the equity outcome can be further adjusted by the redistribution of auction revenues, as in the redistribution of tax revenues. Overall, the tax approach sets a price on GHG emissions, and emitters help determine the overall amount of mitigation, while the cap \& trade approach establishes a limit on emissions, and the market for allowances establishes the price (Rose and Stevens 2017).
} 
Table 1 Alternative equity criteria for global warming policy. Source Rose et al. (1998)

\begin{tabular}{|c|c|c|c|}
\hline Criterion & Basic definition & General operational rule & Operational rule for $\mathrm{CO}_{2}$ permits \\
\hline \multicolumn{4}{|c|}{ Allocation-based } \\
\hline Sovereignty & $\begin{array}{l}\text { All nations have an equal right to } \\
\text { pollute and to be protected from } \\
\text { pollution }\end{array}$ & $\begin{array}{l}\text { Cut back emissions in a proportional manner } \\
\text { across all nations }\end{array}$ & $\begin{array}{l}\text { Distribute permits in proportion to } \\
\text { emissions }\end{array}$ \\
\hline Egalitarian & $\begin{array}{l}\text { All people have an equal right to } \\
\text { pollute or to be protected from } \\
\text { pollution }\end{array}$ & Allow emissions in proportion to population & $\begin{array}{l}\text { Distribute permits in proportion to } \\
\text { population }\end{array}$ \\
\hline Ability to pay & $\begin{array}{l}\text { Mitigation costs should vary directly } \\
\text { with national economic well-being }\end{array}$ & $\begin{array}{l}\text { Equalize abatement costs across nations } \\
\quad \text { (gross cost of abatement as proportion of } \\
\text { GDP equal for each nation) })^{\mathrm{a}}\end{array}$ & $\begin{array}{l}\text { Distribute permits to equalize } \\
\text { abatement costs (gross cost of } \\
\text { abatement as proportion of GDP } \\
\text { equal for each nation) }^{\mathrm{a}}\end{array}$ \\
\hline \multicolumn{4}{|l|}{ Outcome-based } \\
\hline Horizontal & All nations should be treated equally & $\begin{array}{l}\text { Equalize net welfare change across nations } \\
\text { (net gain or loss as proportion of GDP } \\
\text { equal for each nation) }\end{array}$ & $\begin{array}{l}\text { Distribute permits to equalize net } \\
\text { welfare change (net gain or loss as } \\
\text { proportion of GDP equal for each } \\
\text { nation) }^{\mathrm{b}}\end{array}$ \\
\hline Vertical & $\begin{array}{l}\text { Welfare gains should vary inversely } \\
\text { with national economic well-being; } \\
\text { welfare losses should vary directly } \\
\text { with GDP }\end{array}$ & $\begin{array}{l}\text { Progressively share net welfare change } \\
\text { across nations (net gain (loss) proportions } \\
\text { inversely (directly) correlated with per } \\
\text { capita GDP) }^{\mathrm{b}}\end{array}$ & $\begin{array}{l}\text { Progressively distribute permits (net } \\
\text { gain (loss) proportions inversely } \\
\text { (directly) correlated with per capita } \\
\text { GDP) }\end{array}$ \\
\hline Compensation & No nation should be made worse off & Compensate net losing nations & $\begin{array}{l}\text { Distribute permits so no nation suffers } \\
\text { a net loss of welfare }\end{array}$ \\
\hline \multicolumn{4}{|l|}{ Process-based } \\
\hline $\begin{array}{l}\text { Rawls' } \\
\text { maximin }\end{array}$ & $\begin{array}{l}\text { The welfare of the worst-off nations } \\
\text { should be maximized }\end{array}$ & $\begin{array}{l}\text { Maximize the net benefit to the poorest } \\
\text { nations }\end{array}$ & $\begin{array}{l}\text { Distribute largest proportion of net } \\
\text { welfare gain to poorest nations }\end{array}$ \\
\hline Consensus & $\begin{array}{l}\text { The international negotiation process is } \\
\text { fair }\end{array}$ & Seek a political solution promoting stability & $\begin{array}{l}\text { Distribute permits in a manner that } \\
\text { satisfies the (power-weighted) } \\
\text { majority of nations }\end{array}$ \\
\hline Market justice & The market is fair & Make greater use of markets & Distribute permits to highest bidder \\
\hline
\end{tabular}

${ }^{\mathrm{a}}$ Gross cost refers to abatement cost only and does not include benefits or permit transactions

${ }^{\mathrm{b}}$ Net welfare change (gain or loss) is equal to the sum of mitigation benefits - abatement costs + permit sales revenues - permit purchase costs

respond to a price signal; therefore, some regulation would be necessary in what is likely to be a mixed system. ${ }^{2}$

The issue is how forward progress can be made in establishing a truly global emissions trading system to address this transboundary problem. Rose et al. (2018) have suggested a series of stages, starting with leadership in 2020 by G20 countries that have made unconditional pledges and that currently have at least partial emissions trading programs (for example, China and the United States), moving to full emissions trading among all the G20 countries in 2025, and then to a global system of all 195

\footnotetext{
2 To be effective, a price must be positive, and this is not the case for energy-efficiency improvements. Analysts have long marveled at the fact that there is such a large under-attainment of these options when in fact they are cost-saving. They attribute the problem to various forms of "bounded rationality" (Girgerenzer and Selten 2002), such as myopia (disregard for investments with relatively long payback periods), inability to process information, and split incentives (as between owners and renters).
}

signatories to the Paris Agreement in 2030. An emissions trading system involving all countries and regions that made unconditional pledges at Paris could reduce total GHG mitigation costs from an estimated USD 1.71 trillion with no emissions trading to USD 0.4 trillion (in 2015 dollars), a savings of $77 \%$. The ensuing allowance sales revenues would greatly enhance the capability of lowerincome countries to meet their COP21 pledges. Moreover, the cost-savings in high-income countries would facilitate contributions to the promised Cleaning Environment Fund of USD 100 billion per year to assist climate policy implementation in low-income countries. ${ }^{3}$

Ironically, although the efficiency gains of a global emissions trading system are great, the equity outcomes may be problematic. Of course, all parties gain from

\footnotetext{
${ }^{3}$ Rose et al. (2018) find that simply auctioning $13.5 \%$ of the allowances to industrialized countries would yield this USD 100 billion.
} 
trading (allowance buyers incur overall lower costs as mitigation cost savings exceed allowance purchase costs, and allowance sellers' higher mitigation costs are more than offset by revenues from selling allowances), the industrialized countries absolute and relative gains are generally greater than those of low- and middle-income countries (Rose et al. 2017). This too may make the Paris Accord tenuous in addition to other considerations both political and institutional (Averchenkova and Bassi 2016).

Of course, progress on climate change mitigation policy at the international level is only the starting point, and implementation issues at the country, regional, and local levels need to be worked out. Distributional issues arise in these contexts though to a different degree, in a manner somewhat similar to the discussion in the following section (Oladosu and Rose 2007).

\section{Distributional Aspects of Natural Hazard Mitigation and Resilience}

In this section, we discuss the importance of distributional considerations in relation to natural hazards and related environmental threats. The emphasis is less on equity considerations than on how distributional information can supplement standard aggregate benefit-cost analysis to promote public participation in decision making both within and across jurisdictions.

\subsection{Background}

While equity issues soon rose to the forefront of climate change policy negotiations, such issues generally have been in the background of mitigation policy for ordinary (short-run, infrequent extreme event) hazards for several reasons. First, the spatial reach of ordinary hazards is nowhere as great as those of climate change, and hence less of a transboundary issue. ${ }^{4}$ They are thus less in need of interjurisdictional cooperation in terms of burden sharing. Hazard risk reduction for many large countries, such as the United States, China, Russia, India, and Brazil, typically does not require the involvement of other countries, and thus the political authority at top government levels can force agreement. At the same time, the importance of public participation in decision making for sustainable

\footnotetext{
4 Given our interconnected world, consisting of networks of networks of infrastructures and extensive supply-chain systems, even some localized natural hazards could result in cascading and global transboundary consequences, not so much in terms of property damage but in terms of business interruption. A good example is a threat that closes the Straits of Malacca [just south of the port of Singapore (Okada 2009)].
}

development brings distributional considerations to the fore at all jurisdictional levels (Godschalk et al. 2003).

The reduction of risk associated with natural hazards is often couched in terms of mitigation, but there are also ways to reduce risk after the disaster strikes by reducing losses associated with business interruption (BI), which just begins at that point and continues until the economy/community has recovered (Rose 2017). For recent larger events, BI has exceeded property damage (for example, Hurricane Katrina). ${ }^{5}$

We confine our use of the term resilience to post-disaster actions, acknowledging, of course, that resilience is a process whereby its capacity can be enhanced prior to the disaster (for example, stockpiling critical materials, purchasing back-up generators); these "tactics" are not implemented, however, until after the disaster has struck. Following Rose (2004, 2007), we make the following distinctions. In general:

(1) Static resilience refers to the ability of the system to maintain a high level of functioning when shocked (Holling 1973). Static economic resilience is the efficient use of remaining resources at a given point in time. It refers to the core economic concept of coping with resource scarcity, which is exacerbated under disaster conditions; and (2) Dynamic resilience refers to the ability and speed of the system to recover (Pimm 1984). Dynamic economic resilience is the efficient use of resources over time for investment in repair and reconstruction. Investment is a time-related phenomenon - the act of setting aside resources that could potentially be used for current consumption in order to re-establish productivity in the future. Static economic resilience does not completely restore damaged capacity and is therefore not likely to lead to complete recovery.

Note that economic resilience can take place at three levels of analysis:

(1) Microeconomic (operation of individual businesses, households, government agencies, for example, conservation of or substitution for critical inputs, use of inventories or excess capacity, relocation, production rescheduling);

(2) Mesoeconomic (operation of industries and markets, for example, the resource-allocation mechanism of the price system); and

(3) Macroeconomic (operation of the economy, for example, supply-chain adjustments, importation of critical inputs, fiscal and monetary policy).

\footnotetext{
5 This is also true for terrorist attacks and technological accidents, such as the September 11 attacks on the World Trade Center and the Chernobyl nuclear power-plant accident, respectively.
} 
Another important delineation in the concept of economic resilience, and resilience in general, is the distinction between inherent and adaptive resilience (Tierney 2007; Cutter 2016). Inherent resilience refers to resilience capacity already built into the system or that can be "prepositioned in advance of the disaster, such as the ability to utilize more than one fuel in an electricity generating unit, the workings of the market system in offering price signals to identify scarcity and value, and established government policy levers. Adaptive resilience is exemplified by actions devised after the disaster strikes, such as undertaking conservation that was not previously thought possible, changing technology, devising market mechanisms where they might not have previously existed (for example, reliability premiums for electricity or water delivery), or devising new government post-disaster assistance programs. It is important to realize that a good amount of resilience is already embodied in the economy at various levels (for example, a firm's ability to substitute inputs, market signals for reallocating resources), and that policies should be designed to capitalize rather than obstruct or duplicate this capacity. At the same time, policy should also be geared to rewarding both types of resilience.

Cross-border cooperation in hazard risk reduction is exemplified by (pre-event) mitigation tactics relating to a river that transcends boundaries, but there are many more examples on the post-disaster side, including the short-run emergency response phase in addition to resilience for this type and other kinds of disasters. ${ }^{6}$ Both these post-disaster phases can be enhanced by such tactics as pooling of resources across jurisdictions (Rose and Kustra 2013). Also, issues of voluntary cooperation arise here, though not as extensively as in the case of climate change. Some of the same equity principles as discussed above are applicable here in negotiations relating to cooperative efforts, but we will focus more below on intrajurisdictional, public-participation issues.

The policy instruments used to implement hazard mitigation and resilience are likely to be different from those of climate change policy, primarily because the context is much less that of a common property resource. ${ }^{7}$ This makes decision making less complicated for short-term

\footnotetext{
${ }^{6}$ Cross-boundary considerations in relation to mitigation differ by hazard type. For example, codes to promote structural reinforcement of buildings are typically just local, as are storm shutters to protect buildings from hurricane force winds, safe rooms to protect people from tornadoes, and retaining walls to protect people and buildings from landslides. On the other hand, flood control is often a transboundary issue.

${ }^{7}$ We omit consideration of actions after climate change impacts have begun to appear, which are referred to as adaptation (for example, building a seawall against sea-level rise, planting drought-resistant crops, human migration). Note also the potential confusion in terminology when we link climate change and ordinary hazards. A
}

hazards, in part because it eliminates free-rider problems. The main distinction, however, is more directly that an entity can reap the full gains of its mitigation and resilience actions and thus requires fewer additional incentives to address the problem. In fact, issues of basic business and household survival are likely to spawn many effective adaptive resilience tactics (Rose 2017). ${ }^{8}$

\subsection{Distributional Information for Public Participation}

In order for public participation to be effective, those involved need to be informed of the implications of various threats and risk reduction policies. The standard approach to policy evaluation is benefit-cost analysis (BCA). While the careful enumeration of all benefits and costs of a threat or deliberate course of action against it is valuable, the analysis is typically done on an aggregate level for a given project, community, or broader jurisdiction. Basing individual support on an aggregate measure, however, implies that participants are altruistic and care only for how the broader community is affected. More realistically, one can conceive of a utility, or decision, function of the following form for a given individual, $i$ :

$U^{i}=f$ (aggregate impacts, own impacts, community equity)

This takes into account how the individual is affected, as well as how others are affected, using the concept of equity to characterize the latter. This broader approach requires information on how individuals are affected by the policy and a consensus on which definition of equity is applicable. Of course this utility function is also applicable to the case of climate change, but the most appropriate decision entity is the individual country and distributional information of implications across countries is emphasized and readily available, unlike the case for more ordinary hazards.

Note also that individuals are affected not only by a specific policy directly, but are also affected by its indirect impacts. For example, the construction and operation of a dam for flood control creates jobs and income that may or may not affect most decision makers in the relevant jurisdiction, although the protection it provides is likely to affect directly a broader number of participants. The

\footnotetext{
Footnote 7 continued

seawall is an example simultaneously of adaptation to climate change and mitigation of storm-surge and flooding.

${ }^{8}$ We acknowledge that there are potential externality and jointproduct effects of both mitigation and resilience that individuals cannot readily capture. These are part of what is now termed the "resilience triple-dividend" (where resilience is used here in the broad sense to include both mitigation and the way we define it above). The reader is referred to Surminski and Tanner (2016) for insights into how these broader gains can be achieved.
} 
construction and operation of a dam will additionally generate ripple, or multiplier, effects, such as stimulating demand for additional inputs through a successive chain of suppliers, inspiring more downstream uses such as recreation in the backed-up waters, and possibly raising wage rates for everyone throughout the jurisdiction. Hence, it is preferable to use one or several economy-wide models, such as input-output, computable general equilibrium, or macroeconometric models. These models all have multisector detail and various ways of evaluating interdependence to estimate economy-wide effects. What they typically lack, however, is an income distribution impact capability. But this can be attained by disaggregating the underlying social accounting matrix, upon which many of these models are based, according to classes of income recipients and by disaggregating consumption by income class as well (Oladosu and Rose 2007; Rose et al. 2012).

Following Rose et al. (1988, 1989), one type of application of a broader model just described would be to fill in an "individual impact matrix" as depicted in Table 2. The entries in each row of the table represent a probability distribution of how individuals in each income bracket are likely to be affected, positively or negatively, by the net of the benefits and costs of a given policy, in this case opening a national forest in the United States to coal mining. The main entries in the table are the number of people in each income bracket distributed across loss and gain categories, and the figures in parentheses provide the percentage of each entry as a proportion of the total number of people in that income bracket. In addition to creating jobs and income directly and indirectly, there are associated risks, including land subsidence, flooding, and water pollution. This does not provide an individual with certainty of how he/she would be affected, but it does provide considerably more insight than would an aggregate BCA. The individual can insert his/her own personal information on occupation and industry of employment (relating to likely income gains) and location (relating to potential damages from mining) to narrow down the likely personal outcome.

Distributional information in this context can also be rearranged for predictive purposes. Rose et al. (1989) translated the individual impact matrix first into a community impact index, by tabulating the number of winners and losers of a given policy. However, not every winner or loser will actually participate because of such factors as transaction cost obstacles (out-of-pocket or opportunity costs of participation) and the fact that some may view their gains or losses to be trivial (depending greatly on income class). The authors showed how such insights can be used to assign weights to individual outcome categories to predict the extent of individual participation and the formation of a majority outcome in practice via a political 
articulation index. Overall, the case study example indicated the following possibility:

- Aggregate net benefits may be negative;

- The majority of people are negatively affected; and

- The majority of people participating are positively affected.

Of course, this framework is less appropriate for issues with truly long-term consequences, such as climate change. Here the distributional issues shift to analyzing outcomes across generations. The problem in such cases is that future generations are not here to represent themselves, so innovative ways need to be found to promote some type of "participation" for them. This is a very worthy area for future research. Transboundary jurisdictional issues pertaining to disasters become more likely the smaller the size of the jurisdictions. This would especially be the case for regions such as Europe, where disasters of even relatively small magnitudes are likely to generate transboundary issues at both the subnational and national levels. In other cases, where subnational jurisdictions, such as states and provinces in the United States and Canada have relatively more autonomy, there's the possibility that subnational jurisdictions might interact on governance with national and subnational entities elsewhere. A good example of this is the fact that the Western Climate Initiative in the United States includes both California and Quebec, and there have been extensive discussions about emissions trading between California and the EU.

Another instance of transboundary issues arise in cases like the previous example of governing a region that attracts many people from other regions, such as commuters or tourists. This raises the issue of whose voice (vote) should count and represents an important intersection of transboundary and participation issues.

\section{Conclusion}

This article has highlighted the importance of distributional information in the context of policies to reduce the risks of long-term climate change and short-term disasters, including those arising from climate variability. We focused on two major uses of this type of information: (1) negotiations of transboundary issues associated with climate change mitigation policy; and (2) public participation issues in the context of more localized hazards. Of course, climate change negotiation at the international level involves participation issues, but this applies to countries rather than individuals, and distributional information here is emphasized much more and is more readily available, at least for intragenerational equity. Likewise, more conventional disasters do involve transboundary issues as well, but this is the exception rather than the rule in comparison to the global nature of climate change. In the case of climate change, we have discussed distributional considerations in relation to GHG emissions trading (cap \& trade), noting how this policy instrument is especially effective at dealing with normative distributional issues such as equity. For disasters, we have discussed distributional information in the context of public participation, emphasizing the positive economic aspects of information dissemination and predicting the outcome of decision processes.

Further research can benefit from the cross-fertilization of the two areas of inquiry in this article. Ultimately, the implementation of global climate change policy takes place at the local level. Although public participation has been a hallmark of such efforts, the majority of information provided is on aggregate benefits and costs rather than on their distribution across socioeconomic groups.

Also, equity issues have been in the background in disaster research and policy making. Although it is wellknown that the poor are typically relatively harder hit by disasters, few in-depth studies have examined the distribution of the costs of (predisaster) mitigation and (postdisaster) resilience. Also, the most prevalent policy instrument to promote risk reduction strategies has been a regulatory one, and this area could well benefit from research and experience on incentive-based approaches from other environmental domains.

Acknowledgements I wish to thank Norio Okada for his helpful comments on an earlier draft of this paper.

Open Access This article is distributed under the terms of the Creative Commons Attribution 4.0 International License (http://crea tivecommons.org/licenses/by/4.0/), which permits unrestricted use, distribution, and reproduction in any medium, provided you give appropriate credit to the original author(s) and the source, provide a link to the Creative Commons license, and indicate if changes were made.

\section{References}

Andresen, S. 2015. International climate negotiations: Top-down, bottom-up or a combination of both? The International Spectator 50(1): 15-30.

Averchenkova, A., and S. Bassi. 2016. Beyond the targets: Assessing the political credibility of pledges for the Paris agreement. London: Grantham Research Institute on Climate Change and the Environment.

Bretschger, L. 2016. Presentation for the Panel on Climate and Energy Policy after the Paris Agreement, Annual Conference of the European Association of Environmental and Resource Economists, Zürich, Switzerland, 24 June 2016.

Cutter, S. 2016. The landscape of disaster resilience indicators in the USA. Natural Hazards 80(2): 741-758.

Ellerman, A.D., and B. Buchner. 2007. The European Union emissions trading scheme: Origins, allocation, and early results. Review of Environmental Economics and Policy 1(1): 66-87. 
Girgerenzer, G., and R. Selten (eds.). 2002. Bounded rationality: The adaptive toolbox. Cambridge: MIT Press.

Godschalk, D., S. Brody, and R. Burby. 2003. Public participation in natural hazard mitigation policy formation: Challenges for comprehensive planning. Journal of Environmental Planning and Management 46(5): 733-754.

Holling, C. 1973. Resilience and stability of ecological systems. Annual Review of Ecology and Systematics 4 (November): 1-23.

IPCC (Intergovernmental Panel on Climate Change). 2014. Fifth assessment report (AR5). Geneva: IPCC.

Okada, N. ed. 2009. International Workshop on Risk Governance of the Maritime Global Critical Infrastructure: Straits of Malacca and Singapore exposed to extreme hazards. Maritime GCI summary workshop report, Kyoto University and International Risk Governance Council (IRGC).

Oladosu, G., and A. Rose. 2007. Income distribution impacts of climate change mitigation policy in the Susquehanna River Basin. Energy Economics 29(4): 520-544.

Pimm, S. 1984. The complexity and stability of ecosystems. Nature 307(5949): 321-326.

Rayner, S. 2010. How to eat an elephant: A bottom-up approach to climate policy. Climate Policy 10(6): 615-621.

Renn, O., and P. Schweizer. 2009. Inclusive risk governance: Concepts and application to environmental policy making. Environmental Policy and Governance 19(3): 174-185.

Rose, A. 1990. Reducing conflict in global warming policy: Equity as a unifying principle. Energy Policy 18(1): 927-935.

Rose, A. 2004. Defining and measuring economic resilience to disasters. Disaster Prevention and Management 13(4): 307-314.

Rose, A. 2007. Economic resilience to natural and man-made disasters: Multidisciplinary origins and contextual dimensions. Environmental Hazards 7(4): 383-395.

Rose, A. 2017. Defining and measuring economic resilience from a societal, environmental and security perspective. Heidelberg: Springer.

Rose, A., and T. Kustra. 2013. Economic considerations in designing emergency management institutions and policies for transboundary disasters. Public Management Review 159(3): 446-464.
Rose, A., and B.K. Stevens. 2017. Policy instruments for mitigating carbon dioxide emissions. In Encyclopedia of sustainability science and technology, ed. A. Meyers, 1-20. Heidelberg: Springer.

Rose, A., G. Davis, and B.K. Stevens. 1989. Who gains and who loses from natural resource policy: Distributional information and the public participation process. Resources Policy 15(4): 282-291.

Rose, A., B.K. Stevens, and G. Davis. 1988. Natural resource policy and income distribution. Baltimore: Johns Hopkins University Press.

Rose, A., B.K. Stevens, J. Edmonds, and M. Wise. 1998. International equity and differentiation in global warming policy. Environmental and Resource Economics 12(1): 25-51.

Rose, A., D. Wei, and F. Prager. 2012. Distributional impacts of greenhouse gas emissions trading: Alternative allocation and recycling strategies in California. Contemporary Economic Policy 30(4): 603-617.

Rose, A., D. Wei, N. Miller, and T. Vandyck. 2017. Equity, emissions allowance trading and the Paris agreement on climate change. Economics of Disasters and Climate Change 1(3): 203-232.

Rose, A., D. Wei, N. Miller, T. Vandyck, and C. Flachsland. 2018. Meeting COP 21 goals through G20 country leadership on greenhouse gas emissions allowance trading systems. Review of Environmental Economics and Policy 12(1): 170-182.

Surminski, S., and T. Tanner, eds. 2016. Realising the resilience triple dividend: A new business case for disaster risk management. Heidelberg: Springer.

Tierney, K. 2007. Businesses and disasters: Vulnerability, impacts, and recovery. In Handbook of disaster research, ed. H. Rodriguez, E. Quarantelli, and R. Dynes, 275-296. Heidelberg: Springer.

UNFCCC (United Nations Framework Convention on Climate Change). 2016. Report of the conference of the parties on its twenty-first session. Addendum part two: Action taken by the conference of the parties, and decisions adopted by the conference of the parties. http://unfccc.int/resource/docs/2015/ cop21/eng/10a01.pdf. Accessed December 6, 2018. 